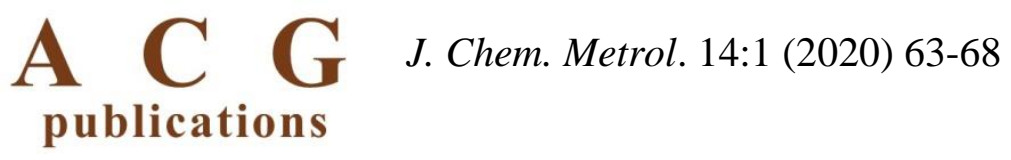

\title{
Determination of doxylamine from a tea sample: A claim of drug facilitated crime
}

\author{
Merve Kuloglu $\odot$ ', Tugba Tekin $\odot{ }^{1}$, Zeynep Turkmen $\odot{ }^{1}$, \\ Y. Tunc Demircan ${ }^{2}$ and Selda Mercan $\odot{ }^{*}$ * \\ ${ }^{1}$ Istanbul University - Cerrahpasa, Institute of Forensic Sciences and Legal Medicine, Department of \\ Science, 34500, Buyukcekmece, Istanbul, Türkiye \\ ${ }^{2}$ Istanbul University - Cerrahpasa, Institute of Forensic Sciences and Legal Medicine, Department of \\ Social Sciences, 34500, Buyukcekmece, Istanbul, Türkiye
}

(Received April 28 2020; Revised June 04, 2020; Accepted June 05, 2020)

\begin{abstract}
Doxylamine, which is an active drug ingredient used for insomnia, is an antihistaminic with sedative effect and can be received without a prescription. Although doxylamine succinate intoxication is encountered quite frequently, there is no data that shows the drug is used for intentional injury. This study was conducted to unravel a suspected case of intentional poisoning facilitated with the use of doxylamine, using a fast, accurate and reliable chromatographic method. The complainant realized that she had fallen asleep after drinking the tea given to her by her colleague, who has been treating her badly for some time. After experiencing a second similar situation, she asked for toxicological analysis. The analysis revealed the presence of $69.3 \mu \mathrm{g} / \mathrm{mL}(13.9 \mathrm{mg} / \mathrm{cup})$ of doxylamine in the sample, and it was concluded that this amount was sufficient to produce the symptoms the complainant mentioned. However, this study reveals that the complainant's claim is quite difficult to prove, and toxicological analysis alone are not enough to prove her claim. Considering the possibility of crimes of intentional injury, aspersion and torment on a legal basis, this study thought to be remarkable as it presents a case of suspected crime facilitated with the use of an active drug ingredient.
\end{abstract}

Keywords: GC-MS; doxylamine; drug-facilitated crime; forensic toxicology; intentional injury. @ 2020 ACG Publications. All rights reserved.

\section{Introduction}

Prescription/non-prescription drug abuse is a complex phenomenon with multiple aspects. This abuse type may include receiving a drug without a prescription or taking a drug with different purposes than it was prescribed for. Drug abuse may lead to addiction and might also cause serious health problems [1]. Doxylamine, which can be bought over the counter, is an antihistaminic substance in the ethanolamine

\footnotetext{
* Corresponding author: E-Mail: mercans@istanbul.edu.tr
} 
class usually formulated with the succinic acid salt, and has a sedative and anticholinergic effect. The action of the drug is based on blocking two important chemicals (histamine, acetylcholine) in body cells. Because of these effects, it is used in treating insomnia, in addition to ease the symptoms of diseases such as allergies, hay fever and common cold [2,3].

Doxylamine is effective at doses up to $25 \mathrm{mg}$, although its sleep-initiating dose is as low as 6.25 $\mathrm{mg}$. For this reason, it is commercially available in $25 \mathrm{mg}$ bisect tablets. Although it varies on an individual basis, the range for the lethal dose of the drug is between $25-250 \mathrm{mg} / \mathrm{kg}$ body weight $[4,5]$. Being one of the common causes of intoxication in emergency departments, taking doxylamine succinate over the effective dose $(25 \mathrm{mg})$ has been reported to cause rhabdomyolysis [4,6-9]. In a study conducted among emergency patients in Korea, it was reported that doxylamine poisoning was frequently encountered [6]. Similarly, in our country, a case in the emergency room due to doxylamine poisoning has been reported, with anticholinergic symptoms such as high blood pressure and tachycardia as a result of taking $650 \mathrm{mg}(11.6 \mathrm{mg} / \mathrm{kg})$ of doxylamine orally [4]. Another case related to doxylamine was reported in a study conducted in Australia, in the biological sample from a case who was found dead together with his mother and brother, a mixture of alcohol and morphine besides doxylamine was detected; it was claimed the mother gave this mixture to her children in a chocolate drink and then hanged herself [10]. Two overdose cases of doxylamine have also been reported in another study with high concentrations found in the blood and organs [11]. In addition, there are studies showing that doxylamine is used in drugfacilitated crimes such as date rape, sexual assault, theft, extortion, etc. [12,13].

The competition brought by the developing working conditions in today's world affects business relations negatively also leads to problems that decrease the efficiency of the working environment, while increases the number of mobbing cases. These kinds of situations bring along security problems, in addition to psychological and physiological health problems for employees [14,15].

In this study, it was aimed to evaluate an alleged intentional injury, which is claimed to have been committed using doxylamine as a sedative substance. This intentional injury claim seen as a mobbing case by the complainant was examined in the light of forensic toxicology studies and it was discussed whether the toxicological analysis results alone will be sufficient in proving the claim.

\section{Materials and Methods}

\subsection{Chemicals and Equipment Used in the Study}

In the analytical steps of the study, sodium hydroxide $(\mathrm{NaOH})$, methanol $(\mathrm{MeOH})$, ethyl acetate and $n$-heptane were used (Merck, 99.8-100\%, Darmstadt, Germany). $n$-docosane (Sigma, 99\%, MO, USA) was preferred as the internal standard (IS). Doxylamine succinate salt (Merck 98\%, MO, USA) was used for quantification studies. $\mathrm{pH}$ measurements were made using a Thermo Scientific, Orion 3Star (Beverly, USA) $\mathrm{pH}$ meter. Evaporation under nitrogen gas was performed with HyperVap HV-300 (Gyrozen, Daejeon, South Korea). Agilent HP 7820A Gas Chromatography system (China) combined with Agilent 5977E Mass Spectrometer Detector (USA) was used for chromatographic separation. 30m x $0.25 \mathrm{~mm}$ silica-coated capillary column (HP-5MS 5\% phenyl methyl siloxane, film thickness $0.25 \mu \mathrm{m}$ Agilent) was used as the analytical column. Helium, at $99.999 \%$ purity, was used as the carrier gas for gas chromatography (Okser, Turkey).

\subsection{Case History}

A thirty-nine-year-old woman stated that she had complaints, such as sleep, weakness and dizziness after drinking the beverage she brought in a capped container, which she claimed was black tea, and that she applied for a toxicological screening of this tea sample. In her detailed history, she stated that one of her colleague at the workplace had been behaving her badly for a long time, trying to defame and get her fired. She stated that the verbal abuse of her colleague in question turned physical a few weeks ago, that her colleague offered her a tea, and after drinking this tea, she had drowsiness and fell asleep for a short time. She stated that during this sleep, her colleague exploited the situation, complained about her 
to the employer, accused her of not doing her job and of sleeping at work, as she found out all about these later. After a few days, the same colleague served her tea again, and after drinking a few sips, similar to the previous incident, she had drowsiness and weakness. So, she doubted that this situation may have been due to the effect of the tea she had drunk. She added that he accused her with low performance and drowsiness, and that he left her in a difficult situation at work. She said she thought this might be a mobbing committed by her colleague and kept the rest of the tea for toxicological analysis to confirm her suspicion, then applied to the Forensic Toxicology Laboratory of Istanbul University - Cerrahpaşa, at the Institute of Forensic Sciences and Legal Medicine. The light brownish liquid sample brought to the laboratory was received and stored under suitable conditions for analysis.

\subsection{Sample Preparation and Chromatographic Conditions}

The sample, which was transferred to the laboratory by coding, was delivered as a light brown liquid with a transparent appearance and in a total volume of $20 \mathrm{~mL}$. Systematic toxicological analysis was carried out since an unknown substance was investigated in the sample. By adding $30 \mu \mathrm{g} / \mathrm{mL}$ IS to 3 $\mathrm{mL}$ of the sample, three separate liquid-liquid extractions were performed using an organic solvent mixture of ethyl acetate: $n$-heptane (1:1) at acidic ( $\mathrm{pH} 4-5)$, basic (pH 8-9) and neutral (pH 7) media. The sample was vaporized to dryness under nitrogen blowing, reconstituted with $500 \mu \mathrm{L} \mathrm{MeOH}$ and analyzed by Gas Chromatography-Mass Spectrometry (GC-MS) in scanning mode. The column temperature programming of the GC-MS analysis with a total analysis time of 12.6 minutes was set with the following parameters: $1 \mathrm{~mL} / \mathrm{min}$ flow rate, $5: 1$ split rate, $1 \mu \mathrm{L}$ injection volume, $110^{\circ} \mathrm{C}(1$ minute $)$ inlet temperature, $250^{\circ} \mathrm{C}\left(25^{\circ} \mathrm{C} / \mathrm{min}\right.$ increase +6 minutes of hold time $)$ final temperature. According to the systematic toxicological analysis result, doxylamine substance was detected and a quantitative analysis method for this substance was generated. Detailed validation parameters can be found in supporting information in $\mathrm{S} 1$ for this quantitative method. The tea sample mentioned in the case was reanalyzed with this validated quantitative analysis method and doxylamine concentration was calculated.

\section{Results and Discussion}

In the aforementioned case, as a result of the systematic toxicological analysis of the beverage the person had brought in a capped container, the active ingredient was determined as doxylamine. In the chromatogram shown in Figure S1 (see supporting information), the caffeine substance, which is known to be a natural component in black tea leaves, had a retention time of $6.63( \pm 0.01)$ minutes, while doxylamine was detected at $7.02( \pm 0.02)$ minutes [16]. Figure S1 also presented the overlaid chromatograms of $n$-docosane (IS) spiked blank tea and the questioned samples in order to examine the matrix effect. Any interferences was not observed at the retention time of doxylamine, while caffeine and IS peaks were similar in both samples.

In order to determine whether the detected doxylamine substance is at the level that may cause symptoms such as drowsiness, confusion and weakness, as mentioned in the complainant's testimony, the quantification method mentioned in S1 (see supporting information) was used. Linear range was detected in between $25-250 \mu \mathrm{g} / \mathrm{mL}$ with satisfied correlation coefficient $(>0.999)$. Calibration curve was presented as supporting information in Figure S2. The developed quantitative method was analyzed in three sets at two different concentrations for repeatability, recovery $(\%)$ and precision and they were found to be within acceptable limits. Linearity, recovery, LOD/LOQ and precision results of the method were summarized in Table S1 (see supporting information). The validation of the method carried out based on EURACHEM CITAC Guide [17,18]. It was assumed that the developed method was simple, rapid, cost-effective, sensitive and accurate to quantitate doxylamine substance in soft drinks.

As a result of the request for analyzing the tea sample with the developed method, $69.3 \mu \mathrm{g} / \mathrm{mL}$ of doxylamine was detected in the sample. With the back-calculation based on this obtained concentration, it was assumed that a teacup had an average volume of $200 \mathrm{~mL}$ and the person consumed all the content. In that case, the amount of doxylamine, which was determined to have a concentration of $13.9 \mathrm{mg} / \mathrm{cup}$, was sufficient to create the symptoms as mentioned in the case history [4]. 
When evaluating the case, discussing more than one concept could be necessary for supporting toxicological findings. Considering the claims of the complainant and the doxylamine substance detected in the analyzed sample; rather than the mobbing concept, as claimed by the complainant, the case should be evaluated under the context of intentional injury. There is no explicit provision regulating mobbing either in the Labor Law or the Turkish Penal Code, and as seen in the literature, mobbing has different definitions. According to one definition, mobbing is a form of psychological terrorism directed against a worker in the workplace, carried out in the form of repeated attacks by the employer or other workers, and manifests itself through hostile behaviors such as maltreatment, threat, violence, and humiliation [19]. According to a Swedish researcher Leymann, "Psychological terror or mobbing in working life involves hostile and unethical communication which is directed in a systematic manner by one or more individuals, mainly toward one individual, who, due to mobbing, is pushed into a helpless and defenseless position and held there by means of continuing mobbing activities" [20]. In the scientific literature, it can be seen that mobbing researches focus on psychological terror, especially among those working in the workplace. However, in addition to psychological pressure, mobbing can accommodate one or more acts of sexual assault, insult, injury, torment and similar acts. To be able to talk about mobbing, the behaviors should be systematic and interconnected, have reached an extent that violates the victim's general personal rights, dignity or health, and serve intimidation, difficulty and discrimination [21]. It is generally accepted that the correspondent of mobbing in criminal law is "torment crime". Torment crime, as it is regulated in Article 96 of the Turkish Penal Code; occurs through the commitment of systematic and sustained acts towards anyone, that are against human dignity, and lead to suffering and humiliation. There may be more than one criminal act of injury in a torment crime. In this case, the offender cannot be punished for the crime of injury and torment separately. The lawmaker foresees this situation, keeping the punishment for torment crime relatively more severe than the punishments for crimes of injury. If the complainant's claim is correct in this case, multiple uses of doxylamine in the workplace for mobbing purposes may be considered as a torment crime.

On the other hand, when the case is evaluated within the context of offences against physical integrity within the scope of criminal law, it may be evaluated under Article 86 of Turkish Penal Code (intentional injury). Since, it will be a behavior that deliberately causes pain to the body of another person or deterioration of the health or perception ability of the person, due to a physical act against the physical integrity of the person.

However, if the claim is not true, the person who made the complaint may have added the drug in the tea herself and experienced the symptoms by drinking it, in order to show herself as a victim and to create evidence against her colleague to prove that he had harmed her. In this case, the action taken by the complainant against her colleague will create an "aspersion crime". It would be reasonable to handle this crime within the scope of Article 267 of the Turkish Penal Code. Another problem that needs to be handled legally is the issue of proof. Since there is no regulation about mobbing in the Turkish Law, there is no special regulation regarding the burden of proof. As a matter of fact, the majority of the lawsuits filed with a mobbing claim and the demand for non-pecuniary damages are rejected by the courts. The same is true for the Supreme Court. For example, between 2010 and 2015, only 54 of the 221 cases involving mobbing allegations requested a compensation for non-pecuniary damages, of which only 11 were accepted [22]. In the case of toxicological proof in drug facilitated crimes, several evidences such as substance residue, drug formulations, beverages, dishes, etc. may be encountered besides other evidences that belong to the victim and/or the offender. The findings obtained as a result of analyzing these examples have an important contribution in clarifying the event, but they must be supported by the analysis of biological evidences of the victim [1]. In the aforementioned case, even if the person's biological sample was taken and analyzed in addition to the beverage sample in order to verify the claim of the complainant, and doxylamine was detected in this biological sample; this alone would not be sufficient to prove her claim. Therefore, if the findings obtained from toxicological analysis are to be evaluated, it seems that a definite confirmation of the person's claim is not possible.

Although there are studies showing that the doxylamine substance is used in drug facilitated crimes, no study has suggested that it has been used in crimes such as torment, intentional injury and aspersion [12,13]. In this context, this study is important since it is the first study reported in the literature. When the study is overall evaluated, doxylamine, which has a sedative effect, was found in the existing 
physical sample, and with the developed quantitative analysis method, it was determined that the amount of doxylamine was enough for the alleged symptoms to develop. However, it was concluded that the evidence for torment crime, intentional injury or aspersion, which would be the basis for mobbing allegation, was insufficient. In conclusion, the detection of doxylamine alone as a result of the analysis performed on samples (food/beverage or biological samples) will not be a sufficient evidence that the alleged crimes have been committed. In addition to the forensic toxicology examinations, the claim in question should be clarified with a judicial investigation of the testimony of witnesses, visual records, if any, and other supporting elements.

\section{Acknowledgements}

The Scientific Research Projects Unit of Istanbul University - Cerrahpasa with the project numbered TSA-2017-24125, supported this study.

\section{Supporting Information}

Supporting information accompanies this paper on http://www.acgpubs.org/journal/journal-ofchemical-metrology

\section{ORCID}

Merve Kuloglu: 0000-0002-3670-3168

Tugba Tekin: 0000-0001-6573-8426

Zeynep Turkmen: 0000-0002-8250-7520

Y. Tunc Demircan: 0000-0001-7615-0265

Selda Mercan: 0000-0002-0431-6972

\section{References}

[1] S. Mercan and M. Acikkol (2014). Madde kullanımının kolaylaştırdığı suçlar: maddeler ve etkileri; deliller ve analizleri, J. Forensic Med. 11 (2), 78-96.

[2] S. Videla, M. Lahjou, P. Guibord, Z. Xu, C. Tolra, G. Encina, E. Sicard and A. Sans (2012). Food effects on the pharmacokinetics of doxylamine hydrogen succinate $25 \mathrm{mg}$ film-coated tablets, Drugs $R \& D .12$ (4), 217-225.

[3] İ.T. Uzbay and N. Yüksel (2002). Anksiyete tedavisinde kullanılan ilaçların farmakolojisi ve kullanım güvenliği, Turk. J. Clin. Psych. 5 (Supp1), 14-26.

[4] S. Soyuncu, Y. Cete and A. Aydrin (2011). Doxylamine succinate overdose: case report and literature review, Erciyes Med. J. 33 (2), 141-144.

[5] B. Bockholdt, E. Klug and V. Schneider (2001). Suicide through doxylamine poisoning, Forensic Sci. Int. 119 (1), 38-140.

[6] J.S. Park, Y.S. Yun, S.W. Chung, T.S. Hwang, S.P. Chung, S.J. Jang and S.H. Kim (2000). Incidence and prediction of rhabdomyolysis following doxylamine overdose, J. Korean Soc. Emerg. Med. 11 (1), 120126.

[7] B. Leybishkis, P. Fasseas and K.F. Ryan (2001). Doxylamine overdose as a potential cause of rhabdomyolysis, Am. J. Med. Sci. 322 (1), 48-49.

[8] Y.D. Lee and S.T. Lee (2002). Acute pancreatitis and acute renal failure complicating doxylamine succinate intoxication, Vet. Hum. Toxicol. 44 (3), 165-166.

[9] U. Khosla, K.S. Ruel and D.P. Hunt (2003). Antihistamine-induced rhabdomyolysis, South. Med. J. 96 (10), 1023-1026.

[10] J.L. Pilgrim, E.L. Jenkins, Y. Baber, D. Caldicott and O.H. Drummer (2017). Fatal acute poisonings in Australian children (2003-13), J. Addict. 112 (4), 627-639.

[11] B. Bockholdt, E, Klug and V. Schneider (2001). Suicide through doxylamine poisoning, Forensic Sci. Int. 119 (1), 138-140.

[12] P. Xiang, M. Shen and O.H. Drummer (2015). Drug concentrations in hair and their relevance in drug facilitated crimes, J. Forensic Leg. Med. 36, 126-135. 
[13] M. Deveaux, M. Cheze and G. Pépin (2008). The role of liquid chromatography-tandem mass spectrometry (LC-MS/MS) to test blood and urine samples for the toxicological investigation of drug-facilitated crimes, Ther. Drug Monit. 30 (2), 225-228.

[14] A. Kehribar, Ş.N. Karabela, Y.K. Kart, A. Okur, M. Derya, C. Özgür and F. Çankaya (2017). Çalışma hayatında mobbing: nedenleri, bileşenleri ve ülkemizdeki hukuki durumu, Med. J. Bakirkoy. 13, 1-9.

[15] M.A. Vartia (2001). Consequences of workplace bullying with respect to the well-being of its targets and the observers of bullying, Scand. J. Work Env. Hea. 27 (1), 63-69.

[16] C. Astill, M.R. Birch, C. Dacombe, P.G. Humphrey and P.T. Martin (2001). Factors affecting the caffeine and polyphenol contents of black and green tea infusions, J. Agric. Food Chem. 49 (11), 5340-5347.

[17] EURACHEM/CITAC Guide to Quality in Analytical Chemistry - 3rd edition, 2016.

[18] H. Han, H. Y1lmaz and İ. Gülçin (2018). Antioxidant activity of flaxseed (Linum usitatissimum L) shell and analysis of its polyphenol contents by LC-MS/MS, Rec. Nat. Prod. 12, 397-402.

[19] P. Tınaz (2006). İşyerinde psikolojik taciz (mobbing), Beta Basım Yayım, 8.

[20] Heinz Leymann (1996). The content and development of mobbing at work, Eur. J. Work Organ. Psychol. 5 (2), 165-184.

[21] M.R. Erdem and B. Parlak (2010). Ceza hukuku boyutuyla mobbing, TBB Dergisi. 88, 261-286.

[22] A. Taşkın (2016). Mobbing davalarında ispat sorunu, AHBVÜ-HFD. 20 (2), 391-438.

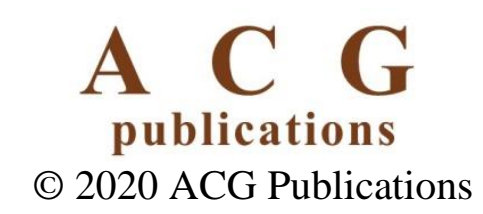

